\title{
A utilização da fosfoetanolamina sintética em pacientes oncológicos: uma análise
}

\section{documental}

\author{
The use of synthetic phosphoethanolamine in cancer patients: a documentary analysis \\ El uso de fosfoetanolamina sintética en pacientes con cáncer: un análisis documental
}

Recebido: 23/02/2021 | Revisado: 03/03/2021 | Aceito: 05/03/2021 | Publicado: 14/03/2021

\author{
Allan Carlos Mazzoni Lemos \\ ORCID: https://orcid.org/0000-0002-7818-9478 \\ Centro Universitário IBMR, Brasil \\ E-mail: allanmazzoni@gmail.com \\ Fábio Machado Araujo \\ ORCID: https://orcid.org/0000-0003-4700-6445 \\ Centro Universitário IBMR, Brasil \\ E-mail: fabiomachadoaraujo@outlook.com \\ Juliane Everton Santos \\ ORCID: https://orcid.org/0000-0003-1539-2329 \\ Centro Universitário IBMR, Brasil \\ E-mail: julianeeverton37@gmail.com
}

\begin{abstract}
Resumo
Introdução- A abordagem sobre a fosfoetanolamina sintética (Pho-s) diz respeito à morte das células causadoras do câncer. O papel da enfermagem envolve perceber do paciente significados de mudanças de valores, crenças e atitudes. Método - pesquisa documental de abordagem qualitativa, exploratória - descritiva retrospectiva mediante entrevistas e sessões televisionadas da câmara do senado e deputados, além de matérias jornalísticas documentais e orais, com a utilização de plataforma online. Resultados - O processo de discussão se iniciou com o químico Gilberto Chierice, quando desenvolveu a substância nos anos 1980. A partir de acontecimentos com a Pho-s, como a distribuição sem estudos clínicos comprovados, a discussão foi levada aos tribunais até receber atenção dos parlamentares federais, com isso, avançou para meios jurídicos onde uma comissão foi organizada para se discutir sobre. O projeto foi aprovado pelos deputados federais, autorizando o uso e produção da Pho-s. No entanto, no mesmo ano o STF suspendeu a lei votada no Senado por precisão de uma análise clínica mais aprofundada. Discussão - para correlacionar o quadro complexo do câncer é utilizado a pirâmide das necessidades básicas, Teoria Wanda Horta. Com a disfunção fisiológica ocorrida manifestação do câncer a parte fisiológica fica comprometida e assim a base da pirâmide fica comprometida. A enfermagem tem um papel importante nesse processo, restabelecendo o equilíbrio do indivíduo e a restauração da parte fisiológica. Considerações finais - o papel da equipe multiprofissional para atender as demandas dos pacientes oncológicos é de grande valia para a recuperação do paciente.
\end{abstract}

Palavras-chave: Enfermagem oncológica; Anaerobiose; Terapia farmacológica adjuvante.

\begin{abstract}
Introduction- The approach on synthetic phosphoethanolamine (Pho-s) concerns the death of cancer-causing cells. The role of nursing involves perceiving the patient meanings of changes in values, beliefs and attitudes. Method documentary research of qualitative, exploratory approach - retrospective descriptive through interviews and televised sessions of the House of The Senate and Deputies, as well as documentary and oral journalistic articles, with the use of an online platform. Results - the discussion process began with the chemist Gilberto Chierice, when he developed the substance in the 1980s. From events with Pho-s, such as distribution without proven clinical studies, the discussion was brought to court until receiving attention from federal parliamentarians, thereby advancing to legal means where a commission was organized to discuss. The bill was approved by federal deputies, authorizing the use and production of Pho-s. However, in the same year the Supreme Court suspended the law voted in the Senate for accuracy of further clinical analysis. Discussion - to correlate the complex picture of cancer is used in the pyramid of basic needs, Theory Wanda Horta. With the physiological dysfunction that has occurred manifestation of cancer the physiological part is compromised and thus the base of the pyramid is compromised. Nursing plays an important role in this process, restoring the balance of the individual and the restoration of the physiological part. Final considerations - the role of the multidisciplinary team to meet the demands of cancer patients is of great value for patient recovery.
\end{abstract}

Keywords: Oncology nursing; Anaerobiosis; Adjuvant drug therapy. 


\begin{abstract}
Resumen
Introducción- El enfoque sobre la fosfoetanolamina sintética (Fo-s) se refiere a la muerte de las células causantes del cáncer. El papel de la enfermería consiste en percibir el significado del paciente de cambios en los valores, creencias y actitudes. Método - investigación documental de enfoque cualitativo, exploratorio - retrospectiva descriptiva a través de entrevistas y sesiones televisadas de la Cámara de Senadores y Diputados, así como artículos periodísticos documentales y orales, con el uso de una plataforma en línea. Resultados - el proceso de discusión comenzó con el químico Gilberto Chierice, cuando desarrolló la sustancia en la década de 1980. A partir de eventos con fo-s, como la distribución sin estudios clínicos probados, la discusión fue llevada a los tribunales hasta recibir atención de los parlamentarios federales, avanzando así a los medios legales donde se organizó una comisión para discutir. El proyecto de ley fue aprobado por diputados federales, autorizando el uso y producción de fo-s. Sin embargo, en el mismo año la Corte Suprema suspendió la ley votada en el Senado para la exactitud de más análisis clínicos. Discusión - para correlacionar la compleja imagen del cáncer se utiliza la pirámide de necesidades básicas, Teoría Wanda Horta. Con la disfunción fisiológica que ha ocurrido manifestación del cáncer la parte fisiológica se ve comprometida y por lo tanto la base de la pirámide se ve comprometida. La enfermería desempeña un papel importante en este proceso, restaurando el equilibrio del individuo y la restauración de la parte fisiológica. Consideraciones finales - el papel del equipo multidisciplinario para satisfacer las demandas de los pacientes con cáncer es de gran valor para la recuperación del paciente.
\end{abstract}

Palabras clave: enfermería oncológica; Anaerobiosis; Terapia farmacológica adyuvante.

\title{
1. Introdução
}

Segundo o Instituto Nacional do Câncer (INCA), o total de novos casos de neoplasias em homens são trezentos e nove mil setecentos e cinquenta (309.750), já em mulheres os casos estão em trezentos e dezesseis mil duzentos e oitenta (316.280). Em mulheres os maiores casos são de câncer de mama, com 29,7\% dos casos e nos homens são os cânceres de próstata com 29,2\% Instituto Nacional do Câncer [INCA] (2020)

O câncer é uma doença que se caracteriza pela multiplicação desordenada de células e se multiplica a partir dos vasos sanguíneos. Células que foram alteradas na sua forma e código genético migram através da corrente sanguínea e se alojam em outros órgãos ou tecidos. A primeira fonte, primata humano, conhecida de câncer diagnosticado data de 35 mil anos, em um neandertal na Alemanha, na região de Stetten. Em animais data de 350 milhões de anos e foi detectado em um fóssil de peixe Oliveto (2015).

Quando os mecanismos de regulação que limitam a divisão celular estão defeituosos e as células se dividem desordenadamente, o resultado é o câncer. A causa direta é quase sempre um defeito genético em uma ou mais das proteínas que regulam a divisão celular Lehninger (2019).

Devido a essa multiplicação desordenada, as células cancerígenas precisam de uma demanda de oxigênio maior, para que isso aconteça há uma sinalização de fatores de crescimento endotelial vascular, da sigla em inglês (VEGF). Uma característica saliente de muitos tumores é que eles residem em um ambiente de baixo oxigênio (hipóxia) variando de 0 a $2 \%$ O2 porque a taxa de proliferação de células tumorais muitas vezes excede a taxa de formação de novos vasos sanguíneos (angiogênese) Boarim et al. (2015)

A adaptação metabólica à hipóxia é coordenada pelo HIF-1, que induz genes metabólicos envolvidos no aumento do fluxo glicolítico. Alguns tumores apresentam ativação constitutiva do HIF-1 sob condições normais através de uma variedade de mecanismos, incluindo (i) hiperativação de mTORC1, (ii) perda de von Hippel-Lindau, (iii) acúmulo de ROS, e (iv) acúmulo de metabólitos do ciclo TCA succinato ou fumarato devido a mutações específicas do câncer em desidrogenase succinato (SDH) ou hidratado de fumarato (ESF), respectivamente Raychaudhuri et al. (2019)

Com a maior irrigação e nutrição o tecido pode crescer e se multiplicar ainda mais rápido e migrar para outros locais. Assim, existem regiões do tumor que não recebem um fluxo de oxigênio considerável e crescem em hipóxia, principalmente nas regiões centrais das células. A baixa de oxigênio induz a célula a líse de aminoácidos no metabolismo da gliconeogênese para substituir a glicose na manutenção e crescimento das células mutagênicas Boareto et al. (2015) 
Estudos mostram que as células glicolíticas são susceptíveis à morte celular quando sujeitas a baixa disponibilidade de glicose ou à falta dela Boareto et al (2015). No entanto, algumas células cancerosas, incluindo as glicolíticas, podem, de forma eficiente, adquirir maior tolerância à depleção de glicose, levando a sua sobrevivência (resistência) e agressividade Palorini et al. (2016)

A sinalização da quinase A (PKA), enzima envolvida no controle do ciclo celular, proliferação, diferenciação, migração celular e metabolismo, é fundamental para o desenvolvimento da resistência de células cancerígenas à inanição da glicose. Demonstraram ainda que a inibição da PKA resultou no aumento da taxa de morte celular pela ativação da autofagia. Com isso, concluíram que a autofagia e os mecanismos ativados pela PKA são importantes para o crescimento celular em um ambiente em que haja privação de glicose. Palorini et al. (2016)

A ativação das vias de sinalização e das vias metabólicas compensatórias é apontada como uma explicação para a resistência aumentada à inanição de glicose, característica apresentada pelas células tumorais. Durante o crescimento, a glicose é utilizada para gerar energia (ATP), bem como para produzir biomassa (lipídeos, aminoácidos e nucleotídeos). Para produzir duas células filhas viáveis na mitose, uma célula em proliferação deve replicar todo seu conteúdo celular, impondo uma exigência de biomassa. ATP Amorim et al. (2018)

A velocidade de crescimento do tumor resultará em um aumento exacerbado dessa exigência e da velocidade de produção dessas moléculas, fatores que irão guiar quais as vias metabólicas devem ser ativadas. Heiden et al. (2009)

A partir daí, pode-se entender o porquê, apesar de gerar mais ATP, o metabolismo aeróbico contraria as necessidades para uma proliferação rápida das células tumorais. Isso explica em parte, os achados por Warburg, em que mesmo na presença de oxigênio, uma célula tumoral degrada a glicose até piruvato (glicólise aeróbica) e simultaneamente o converte em ácido lático (metabolismo anaeróbico). Ainda nesse sentido, Heiden, Cantley e Thompson relatam que, considerando o tempo necessário para a formação de ATP e biomassa a partir de uma molécula de glicose, é mais eficaz utilizar o metabolismo anaeróbico do que o aeróbico. Heiden et al. (2009)

A fosfoetanolamina é um composto natural, presente na bicamada fosfolipídica e tem efeito antitumoral na sua forma sintética. A sua atuação nos organismos afetados pelas mutações gênicas é diminuir a atividade de multiplicação celular mitótica, principalmente nas fases das divisões S (duplicação de DNA, síntese de RNA e proteínas), G2 (manutenção da fase S) e M (o processo de mitose, propriamente dito e a citocinese - multiplicação da célula em duas. Ferreira et al. (2013)

Os mecanismos de controle da multiplicação celular voltam a funcionar e o tamanho dos tumores regride, a partir da atuação da enzima Caspase - 3, que atua como um dos reguladores do processo de divisão celular. Além disso, o retorno do processo de suicídio programado - Apoptose - que atua como um regulador do crescimento, envelhecimento e reciclagem das células eucariontes. A apoptose interrompe a ação de um DNA mutagênico, que pode alterar o funcionamento de uma célula saudável em um tumor e por isso o seu funcionamento é primordial ao organismo. Ferreira et al. (2011)

O papel da enfermagem, enquanto equipe é de perceber o paciente com câncer traz significados diversos, mudanças de valores, crenças e atitudes que demandam intervenções apropriadas e individualizadas, para minimizar a ameaça à sua integridade física e psíquica, o que leva a enfermeira, e demais profissionais de sua equipe, a confrontar-se com sua própria vulnerabilidade e finitude. Silva e Cruz (2011)

Assistir ao paciente com câncer vai além de uma prescrição de cuidados: envolve acompanhar sua trajetória e de sua família, desde os procedimentos diagnósticos, tratamento, remissão, reabilitação, possibilidade de recidiva e fase final da doença, ou seja, vivenciando situações do momento do diagnóstico à terminalidade. Silva e Cruz (2011)

O impacto que uma doença provoca sofre interferência de alguns fatores, como sua Adoecer por câncer é uma experiência que ultrapassa o corpo físico, embora nele se instale e desenvolva sentimentos e significados, estes interpretados e reinterpretados tanto pela pessoa doente quanto por aquelas com as quais convive. Silva e Cruz (2011); Maruyama (2006) 
A compreensão desses aspectos pode direcionar o profissional de enfermagem a olhar para além da pessoa doente. Isto porque a cronicidade, a repercussão que esta pode gerar, quer seja do ponto de vista das alterações orgânicas ou em relação às questões afetivas, emocionais e sociais. Ou seja, a doença traz em si um significado individual, que é pessoal, mas também tem um significado coletivo, que é social Silva e Cruz (2011). Além disso, compreender como a doença oncológica mobiliza toda a dinâmica familiar faz com que a equipe de enfermagem, ao direcionar e planejar a assistência, possa fazê-lo de uma maneira mais abrangente, porém individualizada, de qualidade, e que contribua para um melhor enfrentamento da doença. Silva e Cruz (2011)

Assim, é de fundamental importância a relação profissional-paciente no processo de adesão ao tratamento, visto que existem fatores aí envolvidos que são próprios do contexto em que o paciente está inserido. Por isso, as enfermeiras oncologistas precisam entender e fazer-se entender, e compartilhar com o paciente/família o momento do tratamento como sendo de troca e interação. Silva e Cruz (2011)

Temos como questão norteadora: Em que medida a fosfoetanolamina sintética poderá beneficiar o paciente com câncer? O objeto do estudo é analisar a utilização da fosfoetanolamina sintética em pacientes com câncer. Os objetivos do estudo são os de coletar dados do uso da fosfoetanolamina sintética em pacientes com câncer, descrever uma linha histórica da utilização fosfoetanolamina sintética aos pacientes com câncer, relatar as informações da linha histórica do uso fosfoetanolamina sintética até o momento atual em pacientes com câncer.

O presente estudo torna-se relevante devido a necessidade de esclarecimento do uso da fosfoetanolamina sintética e seu impacto no tratamento contra o câncer e a necessidade de continuidade da pesquisa clínica. O estudo se justifica em acumular dados sobre a fosfoetanolamina sintética e assim entender o seu funcionamento no organismo e o tratamento contra o câncer. Esse entendimento proporcionará para a população acometida por essa doença uma forma de tratamento com um custo menor do que os convencionais e sem efeitos colaterais severos.

\section{Metodologia}

Trata-se de uma pesquisa documental, de abordagem qualitativa, exploratória - descritiva retrospectiva. A análise documental favorece a observação do processo de maturação ou de evolução de indivíduos, grupos, conceitos,conhecimentos, comportamentos, mentalidades, práticas, entre outros. Cellard (2008) Além disso, de acordo com Ludke e Andre (2013) os métodos qualitativos são aqueles nos quais é importante a interpretação por parte do pesquisador com suas opiniões sobre o fenômeno em estudo e isso demonstra que a base do estudo qualitativo é favorecido pela base de dados analisados pelos autores.

De acordo com Gil (2007) utilizaremos 3 fases para dar conta das buscas documentais: Na fase de pré - análise os documentos que geraram a formulação da hipótese foram matérias jornalísticas (online) documentais e orais, com a utilização da plataforma Youtube para buscas de vídeos e relatos abordando a temática incluindo entrevistas e sessões televisionadas da câmara do senado e deputados nas respectivas TV Senado e TV Câmara. Documentos legais que estão disponíveis ao público dos relatos jurídicos igualmente foram utilizados para base da pesquisa.

A fase de exploração do material classifica-se por uma linha temporal de acontecimentos, enumerando os fatos de ocorrência fomentando maior entendimento das ações e fatos.

Elucidando a fase de tratamento dos dados, interpretamos os resultados com inferência à temática através da exploração e organização dos achados em pastas e por ano de acontecimentos e discussões com literatura pertinente. Como critério de inclusão obtivemos uma busca de documentos entre 2015 a 2020 e exclusão de documentos fora desta temporalidade. 


\section{Resultados}

A partir da análise feita das matérias jornalísticas, incluindo: revistas, jornais (online) e reportagens televisivas (vídeos do Youtube), além disso, vídeos na plataforma Youtube com as sessões na Câmara dos Deputados Federais e Senado Federal nos seus respectivos canais TV Câmara e TV Senado.

Ao analisar as matérias jornalísticas percebe-se o quanto o assunto envolvendo a fosfoetanolamina sintética é sensível, tanto para as pessoas que precisam dela quanto para os órgãos que acolhem a sua fabricação ou a sua proibição.

O processo de discussão sobre a fosfoetanolamina sintética se iniciou com o químico Gilberto Orivaldo Chierice, quando do desenvolvimento da substância, nos anos 1980 no laboratório do Instituto de Química, pertencente à Universidade de São Paulo (USP), e sua distribuição gratuita por quase 20 anos, como diz no relato: "Trata-se de um polímero desenvolvido a partir do óleo de mamona. Ele produziu e distribuiu o remédio gratuitamente por 20 anos, embora não houvesse testes clínicos comprovados em humanos..." Sobrinho (2020)

No entanto, o Tribunal de Justiça de São Paulo vetou, no ano de 2014 a distribuição do fármaco, que acontecia na USP de São Carlos e os pacientes que eram atendidos ficaram desabastecidos, como diz o relato: “... embora proibida a distribuição acontecia informalmente até ser expressamente proibida...”. A fosfoetanolamina sintética é a esperança de muitos pacientes com câncer. Mesmo sem comprovação clínica, a substância é entregue para pacientes através de concessão judicial.

Tendo como base a determinação $\mathrm{n}^{\circ} 1389 / 2014$, ... em que a produção e distribuição de drogas com finalidade medicamentosa só pode ser efetuada com a presença de licenças e registros... foi dado como interrompido a produção pelo judiciário, já que a fosfoetanolamina sintética não possui permissão da Anvisa. Advocacia (2015)

A partir daí a discussão foi levado aos tribunais, até receber a atenção dos parlamentares federais, que passaram a fazer pressão para que as pessoas que contavam com o medicamento pudessem ser atendidas, como diz o relato:

"A fosfoetanolamina sintética ganhou destaque no noticiário nacional após virar caso de Justiça. A droga ainda não foi liberada para venda pela Agência Nacional de Vigilância Sanitária (Anvisa), mas alguns pacientes entraram com ações na Justiça para poder se tratar com a substância, que vem sendo apontada como revolucionária no tratamento do câncer. A fosfoetanolamina foi desenvolvida na Universidade de São Paulo (USP) em São Carlos. Porém, a própria USP, a Anvisa e diversas autoridades médicas alegam que a droga não passou por testes em humanos, por isso nem mesmo pode ser considerada um medicamento." Câmara dos Deputados (2015)

Porém, a discussão avançou no meio jurídico e uma comissão foi montada para se discutir com a sociedade, quem produziu, equipe médica e órgãos responsáveis pela aprovação da medicação. "A fosfoetanolamina só poderá ser distribuída em grande escala a partir da autorização da Agência Nacional de Vigilância Sanitária (Anvisa) e do reconhecimento de todas as fases que se exige da pesquisa clínica no Brasil. É de consenso entre o grupo a defesa de critérios rigorosos na aprovação do uso da substância.” Câmara dos Deputados (2015): “consideramos e valorizamos ainda os inúmeros testemunhos que nos chegam. Entretanto, precisamos lembrar que a existência de relatos de cura entre pacientes que recorreram à fosfoetanolamina até o momento ainda não comprova a eficácia da substância contra o câncer. Estudos com seres humanos são necessários (os testes clínicos) para que uma substância seja considerada um medicamento." Câmara dos Deputados (2015)

Com isso fica evidente a necessidade de serem feitos estudos clínicos mais aprofundados e de maior controle para a aprovação da Anvisa, uma vez que poucos estudos clínicos foram feitos. Para além disso, a subcomissão independente que fez ensaios clínicos verificou resultados positivos com o uso da fosfoetanolamina sintética nos ensaios, como diz os relatos de forma respectiva: "O grupo busca através de reuniões com pesquisadores, autoridades sanitárias, governamentais e a partir das evidências apresentadas em audiências públicas, criar as condições necessárias para agilizar as pesquisas clínicas e, ao mesmo 
tempo, buscar garantir o fornecimento continuado para os pacientes que já estão em uso da fosfoetanolamina." Câmara dos Deputados (2015)

"A fosfoetanolamina só poderá ser distribuída em grande escala a partir da autorização da Agência Nacional de Vigilância Sanitária (Anvisa) e do reconhecimento de todas as fases que se exige da pesquisa clínica no Brasil. É de consenso entre o grupo a defesa de critérios rigorosos na aprovação do uso da substância." Câmara dos Deputados (2015)

"O chefe do Laboratório de Imunologia do Instituto Butantã, Durvanei Augusto Maria, defendeu que a fosfoetanolamina tem efeitos comprovados cientificamente no tratamento de vários tipos de câncer, como o de mama, rins, leucemia e na boca. "A fosfoetanolamina tem potencial para ser uma nova droga para o tratamento de tumor na cavidade oral. É a primeira vez que isso acontece", sustentou." Câmara dos Deputados (2015)

O pesquisador apresentou aos parlamentares resultados de pesquisas que, de acordo com ele, comprovam a redução dos tumores e a morte das células do câncer, por meio de imagens que mostram bolhas na superfície das células." Câmara dos Deputados (2015)

A partir dos processos de discussão nas comissões, o projeto de lei PL 4639/16 foi aprovado pelos deputados federais. O projeto de lei autorizava o uso e a produção da fosfoetanolamina sintética como medicamento para as pessoas com câncer.

“A substância é definida como de relevância pública e sua produção, distribuição, prescrição, dispensação e uso poderão ocorrer mesmo sem registro sanitário.Os testes e estudos clínicos sobre essa substância ainda estão em curso e a Anvisa não pode conceder o registro sem a conclusão das pesquisas. Entretanto, a própria Anvisa terá de autorizar os laboratórios que farão a produção e distribuição da fosfoetanolamina sintética.” Câmara dos Deputados (2016)

Após a aprovação na câmara dos deputados o projeto precisava passar no senado federal e foi aprovado por unanimidade. No Senado Federal, a proposta tramitou como o PLC 3/2016, obteve a aprovação na Comissão de Ciência e Tecnologia e na Comissão de Assuntos Sociais daquela Casa e seguiu para apreciação do plenário em regime de urgência. Sua aprovação também ocorre após atestada a segurança e baixa toxicidade da substância, por meio de uma pesquisa clínica financiada pelo Ministério da Saúde e de Ciência, Tecnologia e Inovação.

"A proposta é de autoria de vários deputados federais, incluindo os membros do Grupo de Trabalho (GT) da Fosfoetanolamina Sintética, e segue agora para a sanção da Presidente da República” Agência Senado. (2016)

No entanto, no mesmo ano o Supremo Tribunal Federal suspendeu a lei votada no Senado, porque o Conselho Federal de Medicina e os magistrados entenderam que o fármaco precisa ter sua análise clínica mais aprofundada, antes de ser liberada.

Por maioria de votos, o Plenário do Supremo Tribunal Federal (STF) deferiu nesta quinta-feira (19) medida liminar na Ação Direta de Inconstitucionalidade (ADI) 5501 para suspender a eficácia da Lei 13.269/2016 e, por consequência, o uso da fosfoetanolamina sintética, conhecida como "pílula do câncer". A lei autoriza o uso da substância para pacientes diagnosticados com neoplasia maligna. Supremo Tribunal Federal [STF]. (2016)

Os ministros do Supremo Tribunal Federal (STF), suspenderam a lei que liberava o uso da fosfoetanolamina sintética, no total, foram seis votos pela suspensão provisória da lei. Ainda em votação, o relator Marco Aurélio Mello, considerou haver 
um potencial dano em liberar a substância sem a realização de estudos científicos e registro do medicamento pela Anvisa. STF (2016)

Com quatro votos a favor da liberação para pacientes com câncer terminal, o ministro Edson Fachin considerou que a lei deveria ser mantida pois não caberia ao Estado estabelecer o que o paciente deveria ou não usar como medicamento, evocando direito de autonomia. UOL (2016)

Fachin, Rosa Weber, Dias Toffoli e Gilmar Mendes defenderam que a liberação da substância fosse mantida no caso de pacientes terminais, mesmo sem as devidas pesquisas científicas requeridas pela Anvisa. UOL (2016)

Finalmente, agora pacientes que pretendem utilizar a fosfoetanolamina sintética precisam -por meio de medida judicialsolicitar o uso experimental, com venda e comercialização proibidas. O STF entendeu que a distribuição do fármaco não é de competência do Estado, mas o paciente que quiser optar pelo tratamento alternativo pode fazer a solicitação por meio judicial. "O documento, assinado pelo juiz Flávio Henrique Albuquerque de Freitas, afirma que o Supremo Tribunal Federal (STF) proibiu apenas a distribuição da substância, mas não o direito do paciente de custear o próprio tratamento.” Rebeca (2020)

\section{Discussão}

O câncer é uma doença que afeta todo o sistema do indivíduo e para além disso, também afeta a família, amigos e pessoas próximas do paciente. Para correlacionar esse quadro complexo é imperioso trazer a discussão a teórica Wanda Horta, com a pirâmide das necessidades básicas. (Figura 1)

Figura 1. A hierarquia das necessidades de Maslow - O que é e como funciona.

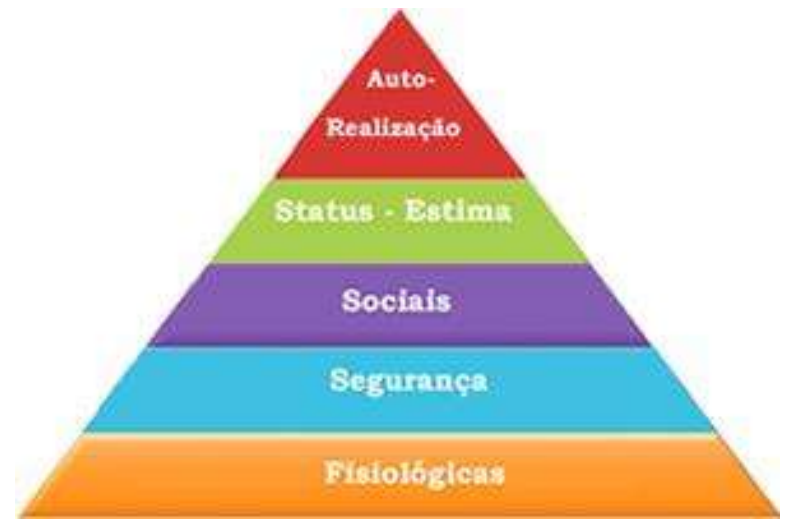

Fonte: https://www.gov.br/infraestrutura/pt-br/assuntos/gestao-estrategica/artigos-gestao-estrategica/a-hierarquia-de-necessidades-de-maslow

A Figura 1, apresenta a hierarquia de necessidades de Maslow, que baseia-se nas condições necessárias para que cada humano atinja a sua satisfação pessoal e profissional, abrangendo um modelo de cinco níveis hierárquicos dentro de uma pirâmide. Esta hierarquia sugere que as pessoas são motivadas a satisfazer as necessidades básicas, antes de passar a outras necessidades mais avançadas. O que pode-se observar é que devido ao estudo fisiológico alterado, os indivíduos passam a ter a base da pirâmide prejudicada e isso impacta diretamente nos outros níveis.

"A enfermagem como parte integrante da equipe de saúde implementa estados de equilíbrio, previne estados de desequilíbrio e reverte desequilíbrios em equilíbrio pela assistência ao ser humano no atendimento de suas necessidades básicas; procura sempre conduzi-lo à situação de equilíbrio dinâmico no tempo e espaço.” De Oliveira (2001 como citado em Horta, 1979) 
Devido a disfunção fisiológica ocorrida pela manifestação do câncer a parte fisiológica fica comprometida e assim a base da pirâmide fica comprometida. A enfermagem tem um papel muito importante, pois é ela quem efetua o processo de cuidar com técnica e prática e restabelecendo o equilíbrio do indivíduo e assim restaurar a parte fisiológica que foi alterada pela doença.

Sendo o ser humano parte integrante do universo, do ponto de vista bio -psico- social, está sujeito a ações do ambiente que o levam a estados de equilíbrio e desequilíbrio. Entende-se "equilíbrio" como a manutenção da harmonia entre o corpo e a mente, sendo que "desequilíbrio" é entendido como a ausência desta harmonia. A enfermagem tem como meta o ato de assistir o ser humano no atendimento de suas necessidades, partindo de um princípio fundamental que é a promoção da saúde e a prevenção da doença. De Oliveira (2001)

Horta conceitua a enfermagem como ciência e a arte de assistir o ser humano. No atendimento de suas necessidades básicas, de torná-lo independente desta assistência, quando possível pelo ensino do autocuidado, de recuperar, manter e promover a saúde em colaboração com outros profissionais. De Oliveira (2001 como citado em Horta 1979)

A fosfoetanolamina é um composto que está classificado entre os fosfolipídios, que é um componente importante na membrana biológica, pois os fosfolipídios têm uma cabeça polar e cauda apolar e interagem entre si formando bicamadas lipídicas, que separam as células do ambiente externo como também transportam substâncias químicas específicas para dentro e fora das células. Da Silva (2016 como citado em Campbell 2000)

A fosfoetanolamina sintética (Pho-s), atua com a finalidade de obter a morte das células causadoras de tumores malignos. Isso é conseguido devido a Pho-s ser uma nova classe de compostos fosfolipídios e tem uma atividade anticâncer promissora e a característica mais importante é que esta nova classe não tem como alvo o DNA. Da Silva (2016 como citado em Ferreira et al 2012)

Esta nova classe inclui substâncias altamente relevantes para o tratamento de tumores malignos, então foi investigado o precursor no centro da biossíntese de fosfolipídios que tem efeitos anti tumorais, assim a fosfoetanolamina um lipídio envolvido com a classe dos fosfolipídios é um substrato para diversos fosfolipídios da célula na membrana e especialmente a fosfatidilcolina, então a partir da pesquisa realizada pelo IQSC-USP foi sintetizada a fosfoetanolamina sendo altamente citotóxica para uma vasta variedade de células tumorais, incluindo o ser humano. Da Silva (2016 como citado em Ferreira et al 2012)

A fosfoetanolamina sintética foi testada em espécies animais e em células cultivadas em laboratório fornecendo resultados bastante favoráveis às expectativas do grupo de pesquisa, no qual percebeu-se a morte destas células com tumores malignos e a redução dos tumores nos animais que possuíam. Da Silva (2016)

\section{Considerações Finais}

Espera-se que os produtos obtidos nesta pesquisa possam contribuir para a ampliação do entendimento do público. Considerando o impacto que uma doença provoca, pode sofrer interferência em alguns fatores, ultrapassando o estado físico da pessoa envolvendo toda uma família e equipe.

A construção desse conhecimento sobre as ações necessárias para a aprovação da Anvisa requer estudos clínicos mais aprofundados e com todas as etapas necessárias concluídas, sendo assim, necessário a aprovação do meio jurídico para um avanço.

Ensaios clínicos feitos com seriedade, segurança e respeitando os processos e assim averiguar a efetividade ou não do fármaco. Além disso, fica evidente a necessidade de um debate público para ampliar a discussão da fosfoetanolamina sintética com profissionais da saúde, os responsáveis pela produção do fármaco para esclarecer de forma imparcial o uso, distribuição e erros cometidos.

Para tanto, a condução da linha histórica do processo da discussão da fosfoetanolamina, além do que é, seu mecanismo de ação e atuação são fundamentais para o entendimento e reafirma a necessidade de novos ensaios clínicos para estabelecer a 
efetividade do fármaco para as pessoas que possuem câncer e assim ter uma opção de tratamento alternativo, além dos convencionais como radioterapia e quimioterapia.

Assim, o papel da equipe multiprofissional para atender as demandas dos pacientes oncológicos é de grande valia para a recuperação do paciente. A enfermagem, com o olhar holístico, permite evidenciar a necessidade de cada indivíduo, estabelecer junto da equipe médica o melhor tratamento para o paciente e assim restabelecer o paciente para a vida normal. Com novos métodos em teste e de forma controlada, associado aos tratamentos convencionais dará maior chances de sobrevivência e qualidade de vida aos pacientes.

Espera-se que com esse texto os ensaios clínicos com a fosfoetanolamina sintética possam retornar e assim novas conclusões possam ser feitas sobre o medicamento e sua eficácia real e comprovada na população que necessita dela. Para próximos estudos que os pacientes que usaram a fosfoetanolamina sintética possam ser ouvidos, suas experiências possam ser relatadas e também relatar os efeitos do medicamento.

\section{Referências}

Advocacia, B. (2015). Justiça concede liminar para liberação da cápsula de fosfoetanolamina aos pacientes com câncer.

Agência Senado. (2016). Projeto da Fosfoetanolamina Sintética é aprovado no Senado, Brasília.

Amorim, M. O. Vieira, M, V. Gonçalves, I. V. Rhana, P. \& Rodrigues, A. L. P (2018). Câncer de mama: Reprogramação do metabolismo tumoral. 28 - 1937. http://www.dx.doi.org/10.5935/2238-3182.20180078.

Boareto, M. J., Mohit, K. B. J., Eshel, O. \& José, N. (2015) Jagged mediates differences in normal and tumor angiogenesis by affecting tip-stalk fate decision Proceedings of the National Academy of Sciences Journal Article Electronic. http://doi.org: 10.1073/pnas.1511814112.

Câmara dos Deputados (2015), Comissão discute o uso da fosfoetanolamina para tratar câncer.

Câmara dos Deputados (2015), Comissão de Seguridade Social e Família (Brasília), Nota Oficial.

Câmara dos Deputados (2015). GT da fosfoetanolamina sintética emite Nota Oficial ao público, Brasília.

Câmara dos Deputados (2015). Pesquisadores reclamam de burocracia na análise da fosfoetanolamina: Anvisa se defende.

Câmara dos Deputados (2016). Câmara aprova projeto que autoriza uso de substância contra o câncer. Brasília.

Cellard, A. (2008) A análise documental. In: Poupart, J. et al. A pesquisa qualitativa: enfoques epistemológicos e metodológicos. Petrópolis, Vozes.

Da Silva, G, R, A. (2016). Abordagem sobre o uso da fosfoetanolamina sintética. Natal, Rio Grande do Norte.

De Oliveira, D. (2001) Processo Sistematizado de enfermagem fundamentado na teoria de Wanda Horta Possibilidades e Limites. Passo Fundo, Santa Catarina.

Ferreira A. K., Meneguelo, R., Pereira, A., Filho, O. M., Chierice, G. O. \& Maria D. A. (2013). Synthetic phosphoethanolamine induces cell cycle arrest and apoptosis in human breast cancer MCF-7 cells through the mitochondrial pathway. Biomed Pharmacother. Jul;67(6):481-7. DOI: 10.1016/j.biopha.2013.01.012. Epub 2013 Feb 16.

Ferreira, A., Meneguelo, R., Neto, S., Chierice, G. \& Maria. (2011). Synthetic Phosphoethanolamine Induces Apoptosis

Through Caspase-3 Pathway by Decreasing Expression of Bax/Bad Protein and Changes Cell Cycle in Melanoma. Journal of Cancer Science \& Therapy. 03. http://doi.org10.4172/1948-5956.1000058.

Gil, A. C. (2007) Como elaborar projetos de pesquisa. (4a ed.), Atlas.

Heiden, M. G. V., Cantley, L. C. \& Thompson C. B. (2009). Understanding the Warburg effect: the metabolic requirements of cell proliferation. Science. http://doi.org10.1126/ science.1160809.

Instituto Nacional do Câncer (2020). Estatísticas de câncer. In: Instituto Nacional do Câncer Causas e Prevenções [Brasília, DF]: Instituto Nacional do Câncer, 2020 .

Lehninger, D (2019). Princípios de Bioquimica. (7a ed.). Artmed, 2019.

Ludke, M. \& Andre, M. E. D. A (2013). Pesquisa em educação: uma abordagem qualitativa. (2a ed.), EPU.

Maruyama S.A.T, Costa A.L.C, Espírito Santo E.A.R, Bellato R. \& Pereira W. R. (2006). O corpo e a cultura como lócus do câncer. Cogitare Enferm. 11(2): $171-75$.

Oliveto, P. (2015). "Primeiro caso de tumor maligno em humanos data de 35 mil anos." 
Research, Society and Development, v. 10, n. 3, e25310313239, 2021

(CC BY 4.0) | ISSN 2525-3409 | DOI: http://dx.doi.org/10.33448/rsd-v10i3.13239

Palorini, R., Votta, G., Pirola, Y., De Vitto H., De Palma, S., Airoldi, C., Vasso, M., Ricciardiello, F., Lombardi, P, P., Cirulli, C., Rizzi, R., Nicotra, F., Hiller, K; Gelfi, C., Alberghina, L. \& Chiaradonna, F. (2016). Protein Kinase A Activation Promotes Cancer Cell Resistance to Glucose Starvation and Anoikis. PLoS Genet; 12(3): e1005931. http://doi:10.1371/journal.pgen.1005931.

Periard G (2018) "A hierarquia das necessidades de Maslow- O que é e como funciona."

Raychaudhuri, D., Bhattacharya, R., Sinha, BP, Liu, C., Ghosh, AR, Rahaman, O., Bandopadhyay, P., Sarif, J., D'Rozario, R., Paul, S., Das, A., Sarkar, D. K., Chattopadhyay, S. \& Ganguly, D. (2019). Lactato induz a reprogramação pró-tumor em células dendríticas plasmocitoides intratumorais. Frontiers in immunology, 10, 1878. https://doi.org/10.3389/fimmu.2019.01878

Rebeca, B (2020). "Paciente com câncer consegue na justiça do Amazonas direito a tratamento não reconhecido pela Anvisa."

Silva, R. C. V. \& Cruz, E. A., (2011) Planejamento da assistência de enfermagem ao paciente com câncer: reflexão teórica sobre as dimensões sociais. Esc. Anna Nery, 15(1), 180-185. http://dx.doi.org/10.1590/S1414-81452011000100025.

Sobrinho, W (2020) "Pílula do câncer: O que é e por que Bolsonaro quer liberar o remédio vetado."

Supremo Tribunal Federal. (2016) "STF suspende eficácia de lei que autoriza uso da fosfoetanolamina."

UOL (2016) “Em decisão liminar, STF suspende lei que liberava "pílula do câncer”. 